\title{
Papers
}

\section{Cancer in children of nuclear industry employees: report on children aged under 25 years from nuclear industry family study}

\author{
Eve Roman, Pat Doyle, Noreen Maconochie, Graham Davies, Peter G Smith, Valerie Beral
}

\begin{abstract}
Objective To determine whether children of men and women occupationally exposed to ionising radiation are at increased risk of developing leukaemia or other cancers before their 25th birthday.

Design Cohort study of children of nuclear industry employees.

Setting Nuclear establishments operated by the Atomic Energy Authority, Atomic Weapons Establishment, and British Nuclear Fuels.

Subjects 39557 children of male employees and 8883 children of female employees.

Main outcome measures Cancer incidence in offspring reported by parents. Employment and radiation monitoring data (including annual external dose) supplied by the nuclear authorities.

Results 111 cancers were reported, of which 28 were leukaemia. The estimated standardised incidence ratios for children of male and female employees who were born in 1965 or later were 98 (95\% confidence interval 73 to 129 ) and 96 (50 to 168) for all malignancies and 109 (61 to 180) and 95 (20 to 277) for leukaemia. The leukaemia rate in children whose fathers had accumulated a preconceptual dose of $\geqslant 100 \mathrm{mSv}$ was 5.8 times that in children conceived before their fathers' employment in the nuclear industry (95\% confidence interval 1.3 to 24.8 ) but this was based on only three exposed cases. Two of these cases were included in the west Cumbrian ("Gardner") case-control study. No significant trends were found between increasing dose and leukaemia.

Conclusions Cancer in young people is rare, and our results are based on small numbers of events. Overall, the findings suggest that the incidence of cancer and leukaemia among children of nuclear industry employees is similar to that in the general population. The possibility that exposure of fathers to relatively high doses of ionising radiation before their child's conception might be related to an increased risk of leukaemia in their offspring could not be disproved, but this result was based on only three cases, two of which have been previously reported. High conceptual doses are rare, and even if the occupational association were causal, the number of leukaemias involved would be small; in this study of
\end{abstract}

over 46000 children, fewer than three leukaemias could potentially be attributed to such an exposure.

\section{Introduction}

The incidence of leukaemia and non-Hodgkin's lymphoma in young people living near certain nuclear establishments in the United Kingdom has been the subject of much research. ${ }^{1-23}$ Of particular concern has been the sustained increased incidence of these cancers in children and young adults living in the Cumbrian village of Seascale, near British Nuclear Fuels' Sellafield reprocessing plant. ${ }^{16} 71821$ In addition, increased rates of leukaemia and non-Hodgkin's lymphoma have been reported in young people living near the Atomic Energy Authority's Dounreay plant ${ }^{49}$ and the Atomic Weapons Establishments at Aldermaston and Burghfield. ${ }^{8}{ }^{13}$

The nuclear industry family study was set up to investigate possible links between child health and parents' occupational exposure to ionising radiation. ${ }^{24}$ Gardner et al's report, ${ }^{10}$ suggesting an association between leukaemia in the under $25 \mathrm{~s}$ and paternal preconceptual exposure to external sources of ionising radiation at work, was published while our study was still at the planning stage. The interpretation of Gardner et al's findings ${ }^{10}{ }^{12}$ continues to be debated, ${ }^{19}$ 25-30 and this paper focuses on our findings for cancer in the under $25 \mathrm{~s}$.

\section{Participants and methods}

Information about the study is given elsewhere. ${ }^{24}$ Briefly, the study population comprised employees of three nuclear authorities: the Atomic Weapons Establishment, the Atomic Energy Authority, and British Nuclear Fuels. All current employees of these three authorities, and past employees of the last two under 75 years old whose details were recorded on the pensions database, were surveyed over the four years 1993 to 1996 . For the purposes of the study, employers provided each subject with a unique personal identifier, which was used to link respondents' data to industry employment and monitoring records (including annual radiation dose).

After undelivered post was excluded, the response rate was $82 \%$ for male workers and $88 \%$ for female

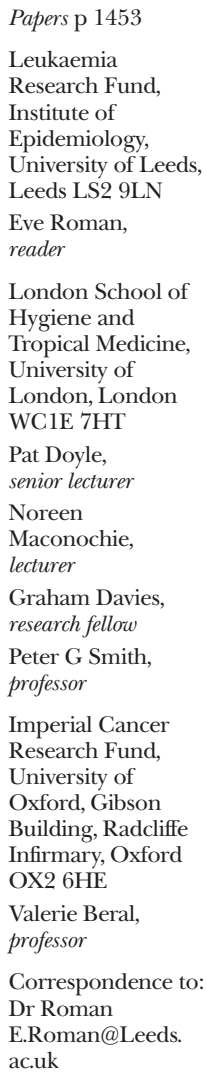

Imperial Cancer Research Fund, University of Oxford, Gibson Building, Radcliffe Infirmary, Oxford OX2 6HE

Valerie Beral, professor

Correspondence to: Dr Roman E.Roman@Leeds. ac.uk

BMJ 1999;318:1443-50

website extra

One further table is available on the BMJ's website

www.bmj.com 
workers, with 39557 live births being reported by 18131 fathers and 8883 by 4435 mothers. ${ }^{24}$ The total number of children in the study was 46 107; 2333 children had both a mother and father in the surveyed population. When a parent reported that one of their children had had a serious illness, such as cancer, more information was requested about the condition and signed consent was sought to access relevant medical notes. Parents were asked to forward consent forms to living children aged 18 years or over.

\section{Statistical methods}

Each child contributed offspring-years at risk from their date of birth until the earliest of the following events: 25th birthday, date of survey, diagnosis of cancer under consideration, or death. Date of conception was estimated as date of birth minus 266 days, except when more precise information on gestational age was available. All analyses were performed with Stata software. ${ }^{31} \mathrm{P}$ values are two sided, with values less than 0.05 indicating significance.

\section{External comparisons}

We obtained annual cancer incidence rates specific for sex and five year age groups for England and Wales, 1971-89 from the Office for National Statistics. National cancer registration in England and Wales did not have an acceptable level of coverage until 1971, ${ }^{32}$ and data for the 1990s were unavailable at the time of analysis. We therefore decided in advance to restrict the comparison with the general population to births occurring in 1965 or later, using average national rates for the five years 1971-5 to estimate rates before 1971 and average rates for the five years 1985-9 to estimate rates after 1989. For births occurring in 1965 or later, offspring-years at risk were stratified by sex, age (five year groups), and calendar period (single years), and the numbers of cancers expected on the basis of the England and Wales rates were calculated. Exact 95\% confidence intervals and $\mathrm{P}$ values for the resulting standardised incidence ratios were based on the Poisson distribution. ${ }^{33}$

\section{Internal cohort comparisons}

We estimated the effect of parental exposure to radiation on the risk of malignancy by rate ratios (hazard ratios) using Cox proportional hazards modelling, with age as the time variable and adjusting for calendar period in 10 year intervals and child's sex. ${ }^{34}$ In analyses of radiation exposure at any time, parental exposure was treated as a time dependent variable. Hence, the same child could contribute offspring-years both to the "unexposed" category (offspring-years occurring before first parental exposure) and to one or more of the "exposed" categories (offspring-years occurring after first parental exposure). For analyses relating to parental exposures occurring before conception, however, all offspring-years were assigned to the same exposure group. Trends of increasing risk with cumulative preconceptual radiation dose were tested by using Cox proportional hazards modelling. Only children whose fathers had been monitored for external sources of ionising radiation before their conception were included in such analyses, the actual preconceptual dose accumulated being modelled using linear, quadratic, or higher order terms.
Because many workers had more than one child in the study, standard errors for the rate ratios were not calculated by standard methods, which assume independence between observations. Instead, we used a robust method based on the "sandwich estimate" of the standard error in all regression analyses. ${ }^{35} 36$ We then assessed the significance of the contribution of variables to the model using the Wald test with the robust variance estimate..$^{3738}$

The hypothesis that occupational preconceptual exposure of fathers to external sources of ionising radiation increases the risk of leukaemia in their offspring derives mainly from the case-control study conducted by Gardner and colleagues. ${ }^{10}$ Gardner et al studied leukaemia and non-Hodgkin's lymphoma in those born in west Cumbria and diagnosed there before their 25th birthday between 1 January 1950 and 31 December $1985 .{ }^{11}$ Because of the potential for overlap with our study, analyses relating to paternal preconceptual exposure were conducted both with and without children born in Cumbria on, or before, 31 December 1985; this last group comprised 5950 $(15 \%)$ children of male workers and $1170(13 \%)$ of female workers.

Table 1 Description of children and malignancies diagnosed before the age of 25 years, reported by parents employed by nuclear authorities. Values are numbers (percentages) of children unless stated otherwise

\begin{tabular}{|c|c|c|}
\hline & \multicolumn{2}{|c|}{ Sex of reporting parent } \\
\hline & Male & Female \\
\hline Total liveborn children & 39557 & 8883 \\
\hline Median length of follow-up (years) ${ }^{*}$ & 23.0 & 22.7 \\
\hline \multicolumn{3}{|l|}{ Year of birth: } \\
\hline Before 1965 & $13995(35)$ & $2829(32)$ \\
\hline $1965-1974$ & $9263(23)$ & $2422(27)$ \\
\hline $1975-1984$ & 8609 (22) & $1480(17)$ \\
\hline $1985-1996$ & 7690 (19) & $2152(24)$ \\
\hline \multicolumn{3}{|l|}{ Age of child at survey (years): } \\
\hline$<5$ & 4487 (11) & $1297(15)$ \\
\hline $5-9$ & $4234(11)$ & $1009(11)$ \\
\hline 10-14 & 4456 (11) & $810(9)$ \\
\hline $15-19$ & $4034(10)$ & $750(8)$ \\
\hline $20-24$ & $4265(11)$ & $1120(13)$ \\
\hline$\geqslant 25$ & $18081(46)$ & $3897(44)$ \\
\hline \multicolumn{3}{|l|}{ Parental monitoringt: } \\
\hline Never monitored & $8034(20)$ & $6683(75)$ \\
\hline Ever monitored & $31523(80)$ & $2200(25)$ \\
\hline Monitored before conception & $15898(40)$ & $801(9)$ \\
\hline \multicolumn{3}{|l|}{ No of malignanciesłף (No validated): } \\
\hline All malignanciesf & $94(92)$ & $22(20)$ \\
\hline Bone§ & $8(8)$ & $2(2)$ \\
\hline Testis & $2(2)$ & 0 \\
\hline Central nervous system§ & $17(17)$ & $7(7)$ \\
\hline Hodgkin’s disease§ & $14(13)$ & $3(3)$ \\
\hline Non-Hodgkin's lymphoma§ & $6(6)$ & $2(1)$ \\
\hline Leukaemia & $22(22)$ & $6(5)$ \\
\hline All other malignancies§ & $25(24)$ & $2(2)$ \\
\hline
\end{tabular}

*Up to the child's 25th birthday, death, or time of survey.

tMonitoring of parent at any time up to the child's 25th birthday, death, or time of survey (including before birth or conception).

†ICD-9 codes: all malignancies (1400-2089, 2250, 2375, 2396); bone (1700-1709); testis (1860-1869); central nervous system (1910-1929, 1943-1944, 2250, 2375, 2396); Hodgkin's disease (2010-2019); non-Hodgkin's lymphoma (2000-2008, 2020-2022, 2024,2026-2029, 2040-2089); leukaemia (2040-2089).

IFive children had both a father and mother in the survey. To preserve confidentiality, site specific data are shown only where there were two or more reports.

§Includes one child with both father and mother in the survey population. 


\section{Results}

The 39557 children of male workers and 8883 children of female workers respectively contributed 716325 and 156304 offspring-years at risk to the analysis. The median length of follow up (up to a maximum 25 years) was 23 years for children of male workers and 22.7 years for children of female workers (table 1). At the time of survey, the oldest child was 58 (born in 1937) and the youngest was less than a month (born in 1996). The proportion of parents monitored for exposure to ionising radiation at some time before their child's 25 th birthday was $80 \%$ for male employees compared with $25 \%$ for female employees. Likewise, although $40 \%$ of children of male employees had a father who was monitored before their conception, only $9 \%$ of children of female employees had a mother who was similarly exposed (table 1 ).

A total of 111 children were reported to have developed a malignancy before their 25th birthday. Five of these, none of whom had leukaemia, had both parents in the study. The earliest year of diagnosis was 1951 and the latest was 1993. Confirmatory evidence in the form of a cancer registration, death certificate, or entry in medical notes was located for $108(97 \%)$ of the 111 children

\section{Comparison with the general population}

Table 2 compares the numbers of cancers diagnosed in children born in 1965 or later, comprising around two thirds of the total population of children, with the numbers expected based on national rates. None of the
Table 2 Numbers of cancers diagnosed in children born in 1965 or later compared with number expected on basis of cancer incidence rates for England and Wales

\begin{tabular}{|c|c|c|c|c|c|c|}
\hline \multirow[b]{2}{*}{$\begin{array}{l}\text { Cancer and } \\
\text { age group } \\
\text { (years) }\end{array}$} & \multicolumn{3}{|c|}{ Father reported } & \multicolumn{3}{|c|}{ Mother reported } \\
\hline & Observed & Expected & $\begin{array}{c}\text { Standardised } \\
\text { incidence ratio } \\
(95 \% \mathrm{Cl})^{\star}\end{array}$ & Observed & Expected & $\begin{array}{l}\text { Standardised } \\
\text { incidence ratio } \\
(95 \% \mathrm{Cl})^{*}\end{array}$ \\
\hline \multicolumn{7}{|c|}{ All malignancies } \\
\hline $0-24$ & 52 & 52.87 & 98 (73 to 129) & 12 & 12.47 & 96 (50 to 168$)$ \\
\hline$\overline{0-14}$ & 36 & 36.50 & 99 (69 to 137) & 9 & 8.30 & 108 (50 to 206$)$ \\
\hline \multicolumn{7}{|c|}{ Leukaemia and non-Hodgkin's lymphoma } \\
\hline $0-24$ & 20 & 16.95 & 118 (72 to 182$)$ & 5 & 3.92 & 127 (41 to 298) \\
\hline$\overline{0-14}$ & 18 & 14.01 & 128 (76 to 203) & 4 & 3.19 & 126 (34 to 321$)$ \\
\hline \multicolumn{7}{|l|}{ Leukaemia } \\
\hline $0-24$ & 15 & 13.71 & 109 (61 to 180$)$ & 3 & 3.17 & 95 (20 to 277$)$ \\
\hline $0-14$ & 14 & 11.96 & 117 (64 to 196) & 3 & 2.73 & 110 (23 to 321$)$ \\
\hline \multicolumn{7}{|c|}{ All malignancies except leukaemia and non-Hodgkin's lymphoma } \\
\hline $0-24$ & 32 & 35.95 & $89(61$ to 126$)$ & 7 & 8.55 & $82(33$ to 169$)$ \\
\hline $0-14$ & 18 & 22.50 & 80 (47 to 126$)$ & 5 & 5.12 & 98 (32 to 228) \\
\hline
\end{tabular}

${ }^{*}$ Adjusted for sex, age (5 year groups), and calendar period (single years).

standardised incidence ratios was significantly different from 100. For all malignancies, the observed and expected numbers among children of male and female workers were almost identical, the ratios for 0 to 24 year olds being 98 (95\% confidence interval 73 to 129$)$ and 96 (50 to 168 ) respectively. The incidence ratios for leukaemia were also close to 100 .

\section{Comparisons within the cohort}

Parental employment and monitoring at any time Table 3 gives the offspring-years at risk and cancers among children of nuclear industry workers classified

Table 3 Cancers and offspring-years at risk in children of nuclear workers, classified according to parental history of employment and monitoring for potential exposure to ionising radiation

\begin{tabular}{|c|c|c|c|c|}
\hline & \multicolumn{2}{|c|}{ Male workers } & \multicolumn{2}{|c|}{ Female workers } \\
\hline & $\begin{array}{c}\text { No of cancers } \\
\text { (offspring-years*) }\end{array}$ & $\begin{array}{c}\text { Rate ratio† } \\
(95 \% \mathrm{Cl})\end{array}$ & $\begin{array}{c}\text { No of cancers } \\
\text { (offspring-years*) }\end{array}$ & $\begin{array}{c}\text { Rate ratio† } \\
(95 \% \mathrm{Cl})\end{array}$ \\
\hline \multicolumn{5}{|l|}{ All malignancies } \\
\hline Before employmentł and monitoring§ & $16(156$ 218) & 1.0 & $8(84165)$ & 1.0 \\
\hline After employment, $\ddagger$ not monitored§ & 10 (123 283) & $0.6(0.3$ to 1.5$)$ & $12(55128)$ & $2.7(1.1$ to 7.0$)$ \\
\hline Monitored (all)§: & $68(436824)$ & $1.2(0.7$ to 2.2$)$ & $2(17011)$ & $1.5(0.3$ to 7.1$)$ \\
\hline External radiation only & $34(228$ 334) & $1.2(0.6$ to 2.2$)$ & $2(10942)$ & $2.3(0.5$ to 10.6$)$ \\
\hline External and internal & $34(208$ 490) & $1.2(0.7$ to 2.4$)$ & $0(6069)$ & $0(-)$ \\
\hline \multicolumn{5}{|l|}{ Leukaemia and non-Hodgkin's lymphoma } \\
\hline Before employment‡ and monitoring§ & $3(156252)$ & 1.0 & $4(84183)$ & 1.0 \\
\hline After employment, $\ddagger$ not monitored§ & $2(123346)$ & $0.7(0.1$ to 4.5$)$ & $4(55163)$ & $1.6(0.4$ to 6.1$)$ \\
\hline Monitored (all)§: & $23(437023)$ & $2.4(0.6$ to 9.5$)$ & $0(17021)$ & $0(-)$ \\
\hline External radiation only & $9(228422)$ & $1.8(0.4$ to 7.9$)$ & $0(10952)$ & $0(-)$ \\
\hline External and internal & $14(208$ 601) & $3.0(0.7$ to 13.0$)$ & $0(6069)$ & $0(-)$ \\
\hline \multicolumn{5}{|l|}{ Leukaemia } \\
\hline Before employmentł and monitoring§ & $2(156253)$ & 1.0 & $4(84153)$ & 1.0 \\
\hline After employment, $\ddagger$ not monitored§ & $2(123346)$ & $1.2(0.2$ to 8.6$)$ & $2(55170)$ & $1.2(0.3$ to 5.5$)$ \\
\hline Monitored (all)§: & $18(437050)$ & $3.2(0.6$ to 15.7$)$ & $0(17021)$ & $0(-)$ \\
\hline External radiation only & $7(228437)$ & $2.4(0.4$ to 13.1$)$ & $0(10952)$ & $0(-)$ \\
\hline External and internal & $11(208$ 613) & $4.1(0.8$ to 21.8$)$ & $0(6069)$ & $0(-)$ \\
\hline \multicolumn{5}{|c|}{ All malignancies except leukaemia and non-Hodgkin's lymphoma } \\
\hline Before employmentł and monitoring§ & $13(156230)$ & 1.0 & $4(84177)$ & 1.0 \\
\hline After employment, $\ddagger$ not monitored§ & $8(123300)$ & $0.6(0.2$ to 1.6$)$ & $8(55$ 159) & $3.9(1.0$ to 14.4$)$ \\
\hline Monitored (all)§: & 45 (436 968) & $1.0(0.5$ to 1.8$)$ & $2(17011)$ & $3.2(0.6$ to 17.8$)$ \\
\hline $\begin{array}{c}\text { External radiation only } \\
\end{array}$ & $25(228360)$ & $1.0(0.5$ to 2.1$)$ & $2(10942)$ & $4.8(0.9$ to 26.4$)$ \\
\hline External and internal & $20(208$ 608) & $0.9(0.4$ to 1.8$)$ & $0(6069)$ & $0(-)$ \\
\hline
\end{tabular}

${ }^{*}$ Offspring-years up to diagnosis, death, or date of survey.

tEstimated rate ratios adjusted for calendar period, age and sex of child, and for the number of children born to each parent.

fAccording to date of first service with nuclear authority in personnel record supplied by employer.

§Monitoring defined as presence of a record of monitoring for external sources of ionising radiation at Atomic Weapons Establishments, Atomic Energy Authority,

British Nuclear Fuels or a previous employer, or date first externally monitored present in personnel record, or flag/date of monitoring for internal radionuclides. 
according to their parents' history of employment in the industries surveyed and monitored for radiation exposure at any time before their child's 25th birthday. For each malignancy group the baseline for all comparisons is the cancer rate in offspring before their parent had a record of employment of monitoring. Data in the second category relate to cancer risk after parental first employment but before first monitoring, and data in the third category to cancer risk after first monitoring.

Relatively few children had mothers who were monitored for external sources of ionising radiation (table 3). Indeed, the rarity of this occupational exposure in women, coupled with the rarity of cancer in the under $25 \mathrm{~s}$ resulted in small numbers of cases in most exposure categories. For example, no leukaemias were reported in children of women who were monitored for exposure to external sources of ionising radiation. Because of lack of data, no further analyses of cancer in children of female employees are presented here.

Among children of male workers, there were no significant variations in cancer risk with paternal history of employment in the nuclear industry or with paternal monitoring for radiation exposure (table 3). Furthermore, there was no evidence that the pattern of rate ratios varied with employer, date of first employment, or whether the respondent was a current or past worker at the time of the survey (data not shown).

\section{Paternal employment before conception}

Table 4 gives the findings relating to paternal employment, monitoring status, and estimated dose of ionising radiation in the preconceptual period. The preconceptual dose groupings are similar to those used by Gardner and colleagues, ${ }^{10}{ }^{12}$ except that children of fathers with a record of monitoring for exposure to ionising radiation for whom there was no recorded dose are included in the lowest dose group (in our data none of the fathers of children with malignancies had recorded doses below $0.1 \mathrm{mSv}$ ).

Table 4 includes more cancers and offspring-years in the baseline category (and correspondingly fewer in the employed and monitored categories) than table 3 because paternal monitoring and employment is considered only to the point of the child's estimated date of conception. For leukaemia, the estimated rate ratio in children whose fathers had a record of monitoring for radiation exposure before their conception was 2.2 ( 0.8 to 6.1 ; based on 12 exposed cases). Among children whose fathers were monitored for external sources alone it was 2.1 ( 0.7 to 6.5$)$ and among children whose fathers were also monitored for radionuclides it was 2.4 (0.7 to 8.3$)$. With respect to recorded whole body dose, the rate ratio for leukaemia in those whose fathers had accumulated a lifetime dose of $\geqslant 100 \mathrm{mSv}$ before their child's conception was 5.8 (1.3 to 24.7). This excess was based on three exposed cases, and the fathers of these three children also had estimated doses in the six months before conception of $10 \mathrm{mSv}$ or more (rate ratio 7.7; 1.9 to 31.0). However, among those who had been monitored for external radiation exposure before their child's conception, there was no significant dose-response relation $(\mathrm{P}$ values for linear and quadratic terms being 0.18 and 0.16 for lifetime exposure and 0.24 and 0.28 for the six months before conception).

The rate ratios for leukaemia calculated after children born in Cumbria before 1986 (potential "Gardner" cases) were excluded are based on even smaller numbers, particularly in the high dose categories (table 4). The numbers of offspring-years at risk, however, are still substantial and the results for leukaemia are similar to those calculated for the total data. Nevertheless, it is important to note that the rate ratio estimates of 6.6 ( 0.7 to 67.1$)$ for a total cumulative preconceptual dose $\geqslant 100 \mathrm{mSv}$ and 11.0 (1.2 to 105.0) for a cumulative dose $\geqslant 10 \mathrm{mSv}$ in the six months before conception were based on only one case.

The raised rate ratios for all malignancies and for leukaemia and non-Hodgkin's lymphoma combined among all children whose fathers accrued a dose of $\geqslant 100 \mathrm{mSv}$ before their conception (and $\geqslant 10 \mathrm{mSv}$ in the six months before conception) were mainly due to leukaemia. The effect of leukaemia was less when Cumbrian births were excluded, the rate ratios for malignancies other than leukaemia and nonHodgkin's lymphoma being 4.0 (1.2 to 13.6, based on three exposed cases) for a lifetime paternal preconceptual dose $\geqslant 100 \mathrm{mSv}$ and 4.4 (1.1 to 18.6, two exposed cases) for a dose $\geqslant 10 \mathrm{mSv}$ in the six months before conception.

So that our results could be compared directly with the record linkage study, ${ }^{22}{ }^{23}$ the analyses were repeated for the first 15 years of life. These results, which are broadly similar to those for 0-24 year olds, are available on the BMJ's website.

\section{Discussion}

The Nuclear Industry Family Study differs in concept and design from other studies that have examined the relation between parental employment in the nuclear industry and child health. It is a within industry investigation, being more analogous to the cohort studies that examined the health of nuclear workers ${ }^{39-44}$ than to the population based case-control studies that have reported on cancer in young people living in areas around nuclear sites. ${ }^{10} 14164546$ The study was resticted to employees of nuclear establishments operated by the Atomic Energy Authority, Atomic Weapons Establishment, and British Nuclear Fuels because each of these industries had at least one plant that had been subject to a report alleging an increased incidence of leukaemia in young people residing in its vicinity. ${ }^{14691014}$

In common with all studies of cancer in offspring of nuclear workers, our findings are based on small numbers of cancers. Although in the case-control studies the small numbers are principally due to the comparative rarity of employment in the nuclear industry, ${ }^{10} 1416224546$ even in areas close to the plants, in our study they largely reflect the rarity of cancer in young people. Of the 46107 children included, only 111 were reported to have had cancer diagnosed before their 25 th birthday and only 28 had leukaemia.

\section{Are children of nuclear industry employees at increased risk of developing cancer?}

Our study, because of its cohort design, has the potential to answer this question directly. Among children born in 1965 or later (two thirds of all children in the 
Table 4 Cancers under age of 25 years in children of male nuclear workers, classified according to paternal employment history before conception, monitoring for radiation exposure, and estimated radiation dose with separate analysis excluding children who may have been included in the study by Gardner et al ${ }^{10}$

\begin{tabular}{|c|c|c|c|c|}
\hline & All ch & & Excluding children bor & mbria before 1986 \\
\hline & $\begin{array}{c}\text { No of cancers } \\
\text { (offspring-years*) }\end{array}$ & $\begin{array}{c}\text { Rate ratio† } \\
(95 \% \mathrm{Cl})\end{array}$ & $\begin{array}{c}\text { No of cancers } \\
\text { (offspring-years*) }\end{array}$ & $\begin{array}{l}\text { Rate ratio† } \\
(95 \% \mathrm{Cl})\end{array}$ \\
\hline All malignancies & & & & \\
\hline Before employment‡ and monitoring§ & $39(379025)$ & 1.0 & 31 (325 479) & 1.0 \\
\hline After employment, $¥$ not monitored§ & 16 (95 115) & $1.5(0.8$ to 2.7$)$ & $14(90478)$ & $1.5(0.8$ to 2.8$)$ \\
\hline Monitored (all)§: & $39(242$ 186) & $1.4(0.9$ to 2.2$)$ & $29(182763)$ & $1.5(0.9$ to 2.5$)$ \\
\hline External radiation only & $23(150648)$ & $1.4(0.8$ to 2.3$)$ & $18(120539)$ & $1.4(0.8$ to 2.6$)$ \\
\hline External and internal & $16(91538)$ & $1.5(0.8$ to 2.7$)$ & $11(62224)$ & $1.6(0.8$ to 3.2$)$ \\
\hline Cumulative external dose $(\mathrm{mSv}) \boldsymbol{\eta}$ : & & & & \\
\hline$<50$ & $29(187$ 197) & $1.4(0.8$ to 2.2$)$ & $23(154736)$ & $1.4(0.8$ to 2.4$)$ \\
\hline $50-$ & $4(26660)$ & $1.3(0.5$ to 3.8$)$ & $2(14880)$ & $1.2(0.3$ to 5.4$)$ \\
\hline$\geqslant 100$ & $6(23431)$ & $2.2(0.9$ to 5.3$)$ & $4(8570)$ & $4.1(1.4$ to 11.8$)$ \\
\hline Estimated cumulative dose in 6 month & & & & \\
\hline$<5$ & 31 (199 180) & $1.3(0.8$ to 2.2$)$ & $25(163$ 313) & $1.4(0.8$ to 2.5$)$ \\
\hline 5- & $3(20026)$ & $1.4(0.4$ to 4.5$)$ & 1 (9 144) & $1.1(0.1$ to 8.1$)$ \\
\hline$\geqslant 10$ & 5 (17 986) & $2.5(1.0$ to 6.5$)$ & $3(5648)$ & $5.1(1.6$ to 16.9$)$ \\
\hline Leukaemia and non-Hodgkin's lympho & & & & \\
\hline Before employmentł and monitoring§ & 11 (379 173) & 1.0 & 7 (325 594) & 1.0 \\
\hline After employment, & $3(95170)$ & $1.0(0.3$ to 3.6$)$ & $3(90527)$ & $1.4(0.3$ to 5.5$)$ \\
\hline Monitored (all)§ & 14 (242 279) & $1.8(0.7$ to 4.4$)$ & 10 (182 841) & $2.2(0.7$ to 6.6$)$ \\
\hline External radiation only & 7 (150 705) & $1.5(0.5$ to 4.2$)$ & $6(120582)$ & $2.0(0.6$ to 7.0$)$ \\
\hline External and internal & 7 (91 574) & $2.3(0.8$ to 6.6$)$ & $4(62259)$ & $2.4(0.6$ to 9.4$)$ \\
\hline Cumulative external dose (mSv)ף: & & & & \\
\hline$<50$ & $10(187255)$ & $1.7(0.6$ to 4.3$)$ & 9 (154 782) & $2.3(0.8$ to 7.2$)$ \\
\hline $50-$ & 1 (26 681) & $1.2(0.2$ to 9.4$)$ & 0 (14 898) & $0.0(-)$ \\
\hline$\geqslant 100$ & $3(23445)$ & $3.9(1.0$ to 15.7$)$ & 1 (8 584) & $4.3(0.5$ to 40.5$)$ \\
\hline Estimated cumulative dose in 6 month & & & & \\
\hline$<5$ & 11 (199 255) & $1.7(0.7$ to 4.3$)$ & $9(613378)$ & $2.2(0.7$ to 6.8$)$ \\
\hline 5- & $0(20030)$ & $0.0(-)$ & $0(9$ 145) & $0.0(-)$ \\
\hline$\geqslant 10$ & $3(18000)$ & 5.4 (1.4 to 20.5$)$ & $1(5661)$ & $7.4(0.8$ to 66.5$)$ \\
\hline Leukaemia & & & & \\
\hline Before employment‡ and monitoring§ & $8(379$ 188) & 1.0 & $5(325607)$ & 1.0 \\
\hline After employment, $\ddagger$ not monitored§ & $2(95$ 181) & $1.0(0.2$ to 4.4$)$ & $2(90538)$ & $1.3(0.3$ to 6.9$)$ \\
\hline Monitored (all)§: & $12(242280)$ & $2.2(0.8$ to 6.1$)$ & $9(182842)$ & $2.9(0.8$ to 10.3$)$ \\
\hline External radiation only & $7(150705)$ & $2.1(0.7$ to 6.5$)$ & $6(120582)$ & $3.0(0.8$ to 11.5$)$ \\
\hline External and internal & $5(91575)$ & $2.4(0.7$ to 8.3$)$ & $3(62260)$ & $2.7(0.6$ to 13.5$)$ \\
\hline Cumulative external dose $(\mathrm{mSv}) \mathrm{m}$ : & & & & \\
\hline$<50$ & $8(187256)$ & $1.9(0.7$ to 5.7$)$ & 8 (154 783) & $3.1(0.8$ to 11.1$)$ \\
\hline $50-$ & 1 (26 681) & $1.7(0.2$ to 14.2$)$ & 0 (14 898) & 0.0 ( to ) \\
\hline$\geqslant 100$ & $3(23445)$ & 5.8 (1.3 to 24.8$)$ & $1(8584)$ & $6.6(0.7$ to 67.1$)$ \\
\hline Estimated cumulative dose in 6 month & & & & \\
\hline$<5$ & 9 (199 257) & $2.0(0.7$ to 5.9$)$ & $8(163379)$ & $2.9(0.8$ to 10.5$)$ \\
\hline 5- & $0(20030)$ & $0.0(-)$ & 0 (9 145) & $0.0(-)$ \\
\hline$\geqslant 10$ & $3(18000)$ & 7.7 (1.9 to 31.0$)$ & $1(5661)$ & $11.0(1.2$ to 105.0$)$ \\
\hline All malignancies except leukaemia ar & ioma & & & \\
\hline Before employment‡ and monitoring§ & 28 (379 093) & 1.0 & 24 (325 543) & 1.0 \\
\hline After employment, $¥$ not monitored§ & $13(95131)$ & $1.7(0.9$ to 3.3$)$ & 11 (90 494) & $1.5(0.7$ to 3.1$)$ \\
\hline Monitored (all)§: & 25 (242 274) & $1.3(0.7$ to 2.2$)$ & 19 (182 834) & $1.3(0.7$ to 2.3$)$ \\
\hline External radiation only & 16 (150 684) & $1.3(0.7$ to 2.4$)$ & $12(120574)$ & $1.2(0.6$ to 2.5$)$ \\
\hline External and internal & 9 (91 590) & $1.2(0.6$ to 2.5$)$ & $7(64260)$ & $1.3(0.6$ to 3.1$)$ \\
\hline Cumulative external dose $(\mathrm{mSv}) \boldsymbol{\pi}$ : & & & & \\
\hline$<50$ & 19 (187 264) & $1.2(0.7$ to 2.2$)$ & 14 (154 803) & $1.1(0.6$ to 2.1$)$ \\
\hline $50-$ & $3(26$ 674) & $1.4(0.4$ to 4.7$)$ & $2(14880)$ & $1.6(0.4$ to 7.2$)$ \\
\hline$\geqslant 100$ & $3(23438)$ & $1.5(0.5$ to 5.0$)$ & $3(8573)$ & $4.0(1.2$ to 13.6$)$ \\
\hline Estimated cumulative dose in 6 month & & & & \\
\hline$<5$ & $20(199261)$ & $1.2(0.7$ to 2.1$)$ & $16(163380)$ & $1.2(0.6$ to 2.2$)$ \\
\hline 5- & $3(20026)$ & $1.9(0.6$ to 6.3$)$ & $1(9$ 145) & $1.4(0.2$ to 10.7$)$ \\
\hline$\geqslant 10$ & 2 (17 993) & $1.4(0.3$ to 5.9$)$ & $2(5652)$ & $4.4(1.1$ to 18.5$)$ \\
\hline
\end{tabular}

*Offspring-years up to diagnosis, death, or date of survey.

†Estimated rate ratios adjusted for calendar period, age and sex of child, and for the number of children born to each parent.

fAccording to date of first service with nuclear authority in personnel record supplied by employer.

§Monitoring defined as presence of a record of monitoring for external sources of ionising radiation at Atomic Weapons Establishment, Atomic Energy Authority,

British Nuclear Fuels or a previous employer, or date first externally monitored present in personnel record, or flag/date of monitoring for internal radionuclides.

ఇCumulative paternal dose. For 947 (3\%) of children (3265 offspring-years) the cumulative dose at conception was not known, either because, although there was

evidence that the father had been internally monitored, there was no external dose record or because the first external dose record was a transfer dose, or because

there was evidence from the personnel record that the father had been monitored but there was no external dose record. 
study) no unusual cancer patterns were evident. The incidence ratios for children of male employees were 98 (95\% confidence interval 73 to 129) for all cancers and 109 (61 to 180) for leukaemia. The findings for children of female employees were similar, although based on fewer cases. Furthermore, internal analysis by parental monitoring and employment also found no firm evidence to suggest that the overall incidence differed greatly from one exposure group to another. We approached employees directly and asked them about the health of their children. Although the response rates were uniformly high and all haematological malignancies reported by fathers were independently corroborated, we cannot be sure that all children and malignancies were notified at survey. However, the fact that the estimated level of cancer in offspring was close to the expected value suggests that there was no overall systematic response bias within the study.

Comparison with results from west Cumbrian study Since the publication of Gardner et al's findings, ${ }^{10}$ discussion about the possible adverse effects of paternal exposure in the nuclear industry has revolved around leukaemia and paternal preconceptual dose of ionising radiation. The authors reported that the highest risk of leukaemia was in children whose fathers had the highest accumulated doses of ionising radiation doses before their conception (both total exposure and in the six months before conception). ${ }^{10}{ }^{12}$ Compared with children of fathers with no record of monitoring for external sources of ionising radiation at Sellafield, children whose fathers had a lifetime cumulative dose $\geqslant 100 \mathrm{mSv}$ before their conception were estimated to be 8.4 (95\% confidence interval 1.4 to 52.0 ) times more likely to develop leukaemia. ${ }^{12}$ The four cases whose fathers had a cumulative preconceptual dose $\geqslant 100$ $\mathrm{mSv}$ received an estimated $10 \mathrm{mSv}$ or more of this dose in the six months before their child's conception, yielding an odds ratio of 6.8 (1.5 to 31.9$).{ }^{12}$ We found rate ratios of 5.8 (1.3 to 24.7) and 7.7 (1.9 to 31.0) for these two dose categories, which is not inconsistent with Gardner et al's results. Furthermore, in both our study and Gardner et al's study, the same cases appeared in both the highest lifetime preconceptual dose group and the highest six months preconceptual dose category. Neither study found any significant trends of increasing risk with increasing dose when analyses were confined to those who had been monitored for radiation exposure before their child's conception.

The population studied by Gardner et al overlaps with ours, and the similarity between the findings must be interpreted with this in mind. We attempted to overcome this problem by conducting some analyses excluding children born in Cumbria before 1986, thereby excluding all children with the potential to have been in the west Cumbrian study. Monitored Sellafield workers had been exposed to higher doses of external ionising radiation, on average, than other workers in the study. Exclusion of children born in Cumbria before 1986 therefore removed proportionally more children from the high dose group than from the low dose group. For example, although all eight cases of leukaemia remained in the $<50 \mathrm{mSv}$ paternal preconceptual dose category, only one remained in the $\geqslant 100 \mathrm{mSv}$ dose category (table 4). For leukaemia, the risk estimates for the high dose categories were similar to those obtained for the total data. These estimates were based, however, on a single case in the highest exposure categories. Furthermore, exclusion of Cumbrian births increased the risk estimates for malignancies other than leukaemia and non-Hodgkin's lymphoma in the higher exposure categories.

\section{Comparison with other studies of preconceptual exposure}

Tables 5 and 6 compare our results with those of four other case-control studies ${ }^{14} 162245$ that considered paternal preconceptual radiation exposure and with those of Gardner et al. ${ }^{10}{ }^{12}$ As with the west Cumbrian investigation, the studies in Caithness, west Berkshire, and Ontario looked only at cases of leukaemia and non-Hodgkin's lymphoma diagnosed in the vicinity of nuclear plants. The record-linkage study aimed at national coverage, using birth certificate identifiers to

Table 5 Summary of studies that have examined cancer risk of cancer in children whose fathers were monitored for occupational exposure to ionising radiation before their conception. ${ }^{*}$ Values are risk ratios $(95 \%$ confidence intervals) unless stated otherwise

\begin{tabular}{|c|c|c|c|c|c|c|c|c|}
\hline & \multirow[b]{2}{*}{ West Cumbria $^{12}$} & \multirow[b]{2}{*}{ Caithness $^{14}$} & \multirow[b]{2}{*}{ West Berkshire $^{16}$} & \multirow[b]{2}{*}{ Ontario ${ }^{45}$} & \multicolumn{2}{|c|}{ Record linkage study ${ }^{22}$} & \multicolumn{2}{|c|}{ Present study } \\
\hline & & & & & All data & $\begin{array}{c}\text { Without } \\
\text { west Cumbria }\end{array}$ & All data & $\begin{array}{l}\text { Without } \\
\text { Cumbria }\end{array}$ \\
\hline \multicolumn{9}{|l|}{ Study description } \\
\hline Age range(years) & $0-24$ & $0-24$ & $0-4$ & $0-14$ & \multicolumn{2}{|c|}{$0-14$} & \multicolumn{2}{|c|}{$0-24$} \\
\hline Years of diagnosis & $1950-85$ & $1970-86$ & $1972-89$ & $1950-88$ & \multicolumn{2}{|c|}{$1952-1986$} & \multicolumn{2}{|c|}{$11951-1993$} \\
\hline \multicolumn{9}{|l|}{ All malignancies } \\
\hline Monitored & No data & No data & No data & No data & $1.3(0.9$ to 1.9$)$ & $1.3(0.9$ to 1.9$)$ & $1.4(0.9$ to 2.2$)$ & $1.5(0.9$ to 2.5$)$ \\
\hline$\geqslant 100 \mathrm{mSv}$ & No data & No data & No data & No data & $1.2(0.3$ to 4.3$)$ & 0.7 (0.1 to 3.4$)$ & $2.2(0.9$ to 5.3$)$ & $4.1(1.4$ to 11.8$)$ \\
\hline \multicolumn{9}{|c|}{ Leukaemia and non-Hodgkin's lymphoma } \\
\hline Monitored & $1.1(0.5$ to 2.7$)$ & Not reported & $9.0(1.0$ to 108.8$)$ & No data & $1.8(1.1$ to 3.0$)$ & 1.8 (1.1 to 3.0$)$ & $1.8(0.7$ to 4.4$)$ & $2.2(0.7$ to 6.6$)$ \\
\hline$\geqslant 100 \mathrm{mSv}$ & $8.6(1.4$ to 52.2$)$ & 0.0 & No data & No data & $1.4(0.3$ to 7.2$)$ & $0.5(0.0$ to 5.2$)$ & $3.9(1.0$ to 15.7$)$ & $4.3(0.5$ to 40.5$)$ \\
\hline \multicolumn{9}{|l|}{ Leukaemia } \\
\hline Monitored & $1.4(0.5$ to 3.9$)$ & Not reported & Not reported & $1.0(0.5$ to 2.2$)$ & Not reported & Not reported & $2.2(0.8$ to 6.1$)$ & $2.9(0.8$ to 10.3$)$ \\
\hline$\geqslant 100 \mathrm{mSv}$ & $8.4(1.4$ to 52.0$)$ & Not reported & No data & 0.0 & Not reported & Not reported & $5.8(1.3$ to 24.8$)$ & $6.6(0.7$ to 67.1$)$ \\
\hline \multicolumn{9}{|c|}{ All malignancies except leukaemia and non-Hodgkin's lymphoma } \\
\hline$\geqslant 100 \mathrm{mSv}$ & No data & No data & No data & No data & \multicolumn{2}{|c|}{$1.0(0.1$ to 13.8$)$} & $1.5(0.5$ to 5.0$)$ & $4.0(1.2$ to 13.6$)$ \\
\hline
\end{tabular}

${ }^{*}$ Further details of these studies are shown in table 6. Results from Kinlen et al's study ${ }^{20}$ are not shown since their data were included in the record-linkage study. ${ }^{22}{ }^{23}$ Findings from the case-control study conducted near the La Hague plant are also not shown since no estimates of risk were reported for monitored workers and there were no reports of workers with doses of $100 \mathrm{mSv}$ or more. ${ }^{46}$ 
Table 6 Further details of studies examining cancer risk in children whose fathers were monitored for occupational exposure to ionising radiation

\begin{tabular}{|c|c|c|c|c|c|c|c|}
\hline \multirow[b]{2}{*}{ Reference } & \multirow[b]{2}{*}{ Cancer type } & \multicolumn{3}{|c|}{ No of cases } & \multicolumn{3}{|c|}{ No of controls } \\
\hline & & Monitored & $\geqslant 100 \mathrm{mSv}$ & Total & Monitored & $\begin{array}{l}\geqslant 100 \\
\mathrm{mSv}\end{array}$ & Total \\
\hline Gardner et al ${ }^{10}(1990,1992)$ & Leukaemia and non-Hodgkin's lymphoma & 10 & 4 & 66 & 58 & 3 & 389 \\
\hline Urquhart et $\mathrm{al}^{14}$ (1991) & Leukaemia and non-Hodgkin's Iymphoma & Not reported & 0 & 12 & Not reported & 1 & 45 \\
\hline Roman et $\mathrm{al}^{16}(1993)$ & Leukaemia and non-Hodgkin's Iymphoma & 3 & 0 & 54 & 2 & 0 & 324 \\
\hline McLaughlin et al $(1993)^{45}$ & Leukaemia & 10 & 0 & 112 & 81 & 5 & 894 \\
\hline \multirow{2}{*}{$\begin{array}{l}\text { Draper et } a^{22} \text { total } \\
\text { (total minus west } \\
\text { Cumbrian cases) }\end{array}$} & Leukaemia and non-Hodgkin's lymphoma & $49(40)$ & $4(1)$ & $13649(13621)$ & $44(38)$ & $5(4)$ & $16023(15995)$ \\
\hline & All other malignancies ${ }^{\star}$ & $33(33)$ & $2(2)$ & 20889 (20 889) & $35(35)$ & $2(2)$ & 20889 (20 889) \\
\hline \multirow{4}{*}{$\begin{array}{l}\text { Present study total } \\
\text { (total minus west } \\
\text { Cumbrian cases) }\end{array}$} & All malignancies & $39(29)$ & $6(4)$ & $94(74)$ & - & - & - \\
\hline & Leukaemia and non-Hodgkin's lymphoma & $14(10)$ & $3(1)$ & $28(20)$ & - & - & - \\
\hline & Leukaemia & $12(9)$ & $3(1)$ & $22(17)$ & - & - & - \\
\hline & All other malignancies* & $25(19)$ & $3(3)$ & $66(4)$ & - & - & - \\
\hline
\end{tabular}

*Excluding leukaemia and and non-Hodgkin's lymphoma.

link UK registration data on all childhood cancers to data on workers included in the National Registry for Radiation Workers. ${ }^{22} 23$

Our study has the potential for overlap with all but the Canadian study. For Caithness and west Berkshire, the potential for overlap is small for children whose fathers were monitored before their conception and negligible for those whose fathers had doses of 100 $\mathrm{mSv}$ or more. We removed cases from west Cumbria to avoid overlap with Gardner et al's study, as did the record linkage study. Case overlap between our study and the record linkage study is harder to overcome because both are national investigations. At first sight the fact that both studies estimated an $80 \%$ increase in the risk of leukaemia and non-Hodgkin's lymphoma among children of monitored workers might be attributed to overlapping data, as around half the fathers in the record linkage study were employed at some time by the industries studied here. ${ }^{22}$ However, in the record linkage study the significantly raised risk of 1.8 (1.1 to 3.0) for leukaemia and non-Hodgkin's lymphoma had its origins in an estimated eightfold increase in risk (95\% confidence interval 1.2 to $\infty$ ) among children with fathers whose estimated doses were below 0.1 $\mathrm{mSv} .{ }^{22} 23$ The removal of potential Gardner cases had no effect on this estimate. This observation, coupled with the knowledge that such low doses were rare in the industries studied here,${ }^{24}$ suggests that the excess

Key messages

- This cohort study examined cancer diagnosed before the age of 25 years in children of workers at three nuclear authorities in the United Kingdom

- Overall the incidence of all cancers and of leukaemia was similar to that expected in the general population

- The possibility that exposure of fathers to relatively high doses of ionising radiation before their child's conception might in some way be related to an increased risk of leukaemia in their offspring could not be disproved, but this result was based on only three cases, two of which have been previously reported in the west Cumbrian ("Gardner") case-control study risk in the record linkage study has its origins elsewhere. The reasons for the disagreement between the studies with data on children whose fathers were exposed to $\geqslant 100 \mathrm{mSv}$ before their conception are unclear.

\section{Conclusions}

The overall incidence of cancer and leukaemia among children of nuclear workers was similar to that in the general population. The estimated risk of leukaemia in children whose fathers were monitored for exposure to radiation at work before their child's conception was about twice that of children conceived before their fathers joined the workforces under study. Though this excess was not significant overall, significant findings were apparent for the small group of children whose fathers were exposed to relatively high doses of radiation before their conception.

Although our study is comprehensive, cancer in young people is rare and our findings are based on small numbers of cases. Our data are too few to break down into non-overlapping exposure periods; fathers exposed to high doses of external ionising radiation immediately before conception were also more likely to be exposed to high doses before that time. Similarly, fathers exposed before their child was conceived were often exposed throughout their child's life. As well as being unable to identify relevant "time windows" of exposure, the nature of the hazardous exposure, if it exists, remains unknown. Furthermore, high preconceptual doses are rare. If there is an occupational effect associated with paternal exposure to relatively high doses of radiation, the number of leukaemias that could be attributed to such an exposure in our study is small-such exposure could account for at most three of the 22 leukaemias diagnosed in almost 40000 reported children born during the 60 years 1937-96.

We thank the many people who contributed to the study, including management and workforce representatives who gave permission for the study to be conducted, industry staff who worked with us and, most importantly, the study participants themselves. We also thank Pat Ansell, Aurora Berra, Beverley Cooper, Patricia Fraser, Juliet Jain, Angela MacCarthy, Tuyet Ngyen, Margo Pelerin, Patrick Sampson, and Amanda Thomas. For supplying employment and dosimetry data, we thank Will Atkinson, Dallas Law and Keith Bromley (Atomic Energy Authority), George Sallit and Pauline Johnson (Atomic Weapons Establishments), and Keith Binks, Sheila Jones, and Les Scott (British Nuclear Fuels). Finally, we thank the scientific 
steering group (Eva Alberman, Tim Bishop, Martin Bobrow, and Dudley Goodhead) for continued support and guidance.

Contributors: ER (guarantor) initiated the research and participated in all aspects of the study. PD participated in protocol design, data collection, analysis, and writing the paper. NM participated in protocol development, data collection, analysis, and writing the paper. GD participated in data collection and analysis. PGS initiated the research and participated in protocol design and writing the paper. VB initiated the research and participated in protocol design and writing the paper.

Funding: Department of Health and Health and Safety Executive.

Competing interests: PS has received funding from British Nuclear Fuels for research on the health of Sellafield workers.

1 Black D. Report of the Independent Advisory Group. Investigation of the possible increased incidence of cancer in West Cumbria. London: HMSO, 1984.

2 Urquhart J, Palmer M, Cutler J. Cancer in Cumbria: the Windscale connection. Lancet 1984;i:217-8.

3 Gardner MJ, Winter PD. Mortality in Cumberland during 1959-78 with reference to cancer in young people around Windscale. Lancet 1984;i:216-7

4 Heasman MA, Kemp IW, Urquhart JD, Black R. Childhood leukaemia in northern Scotland. Lancet 1986;i:266.

5 Committee on Medical Aspects of Radiation in the Environment. First report. The implications of the new data on the releases from Sellafield in the 1950s for the conclusions of the report on the investigations of the possible increased incidence of cancer in west Cumbria. London: HMSO, 1986.

6 Gardner MJ, Hall AJ, Downes S, Terrell JD. Follow up study of children born elsewhere but attending schools in Seascale, west Cumbria (schools cohort). BMJ 1987;295:819-22

7 Gardner MJ, Hall AJ, Downes S, Terrell JD. Follow up study of children born to mothers resident in Seascale, west Cumbria (birth cohort). BMJ 1987;295:822-7

8 Roman E, Beral V, Carpenter L, Watson A, Barton C, Ryder H, et al. Childhood leukaemia in the West Berkshire and Basingstoke and North Hampshire District Health Authorities in relation to nuclear establishments in the vicinity. BMJ 1987;294:597-602.

9 Committee on Medical Aspects of Radiation in the Environment. Second report. Investigation of the possible increased incidence of leukaemia in young people near the Dounreay nuclear establishment, Caithness, Scotland. London: HMSO, 1988

10 Gardner MJ, Snee MP, Hall AJ, Powell CA, Downes S, Terrell JD. Results of case-control study of leukaemia and lymphoma among young people near Sellafield nuclear plant in west Cumbria. BMJ 1990:300:423-9.

11 Gardner MJ, Hall AJ, Snee MP, Downes S, Powell CA, Terrell JD. Methods and basic data of case-control study of leukaemia and lymphoma among young people near Sellafield nuclear plant in west Cumbria. BMJ 1990;300:429-34.

12 Gardner MJ. Paternal occupations of children with leukaemia. BMJ 1992;305:715.

13 Committee on Medical Aspects of Radiation in the Environment. Third report. Report on the incidence of childhood cancer in the west Berkshire and north Hampshire area, in which are situated the Atomic Research Establishment, Aldermaston and the Royal Ordnance Factory, Burghfield. London: HMSO, 1989.

14 Urquhart JD, Black RJ, Muirhead MJ, Sharp L, Maxwell M, Eden OB, et al. Case-control study of leukaemia and non-Hodgkin's lymphoma in children in Caithness near the Dounreay nuclear installation. BMJ 1991:302:687-92.

15 Health and Safety Executive. Investigation of leukaemia and other cancers in the children of male workers at Sellafield. London: HMSO, 1993.

16 Roman E, Watson A, Beral V, Buckle S, Bull D, Baker K, et al. Case-control study of leukaemia and non-Hodgkin's lymphoma among children aged 0-4 years living in west Berkshire and north Hampshire health districts. BMJ 1993;306:615-21

17 Parker L, Craft AW, Smith J, Dickinson H, Wakeford R, Binks K, et al. Geographical distribution of preconceptual radiation doses to fathers employed at the Sellafield nuclear installation, West Cumbria. BMJ 1993;307:966-71.

18 Draper GJ, Stiller CA, Cartwright RA, Craft AW, Vincent TJ. Cancer in Cumbria and in the vicinity of the Sellafield nuclear installation, 1963-90. BMJ 1993;306:89-94

19 Kinlen LJ. Can paternal preconceptional radiation account for the increase of leukaemia and non-Hodgkin's lymphoma in Seascale? BMJ 1993;306:1718-21.

20 Kinlen LJ, Clarke L, Balkwell A. Paternal preconceptional radiation exposure in the nuclear industry and leukaemia and non-Hodgkin's lymphoma in young people in Scotland. BMJ 1993;306:1153-8.

21 Committee on Medical Aspects of Radiation in the Environment. Fourth report. The incidence of cancer and leukaemia in young people in the vicinity of the Sellafield site, west Cumbria:further studies and an update of the situation since the publication of the Black Advisory Group in 1984. London: Department of Health, 1996.

22 Draper GJ, Little MP, Sorahan T, Kinlen LJ, Bunch KJ, Conquest AJ, et al. Cancer in the offspring of radiation workers-a record linkage study. Chilton: Cancer in the offspring of radiation workers-a record linkage stud
National Radiological Protection Board, 1997. (NRPB-R298.)

23 Draper GJ, Little MP, Sorahan T, Kinlen LJ, Bunch KJ, Conquest AJ, et al. Cancer in the offspring of radiation workers: a record linkage study. $B M J$ 1997;315:1181-8.

24 Maconochie N, Doyle P, Roman E, Davies G, Smith P, Beral V. The nuclear industry family study: linkage of occupational exposures to reproduction and child health. BMJ 1999;318:53-4.
25 Evans HJ. Gardner report. Leukaemia and radiation. Nature 1990;345: $16-7$

26 Greaves MF. The Sellafield childhood leukemia cluster: are germ line mutations responsible? Leukemia 1990;4:391-6.

27 Beral V, Roman E, Bobrow M, eds. Childhood cancer and nuclear installations. London: BMJ Publishing, 1993.

28 Doll R, Evans HJ, Darby SC. Paternal exposure not to blame. Nature 1994:367:678-80.

29 Inskip H. Reay and Hope versus British Nuclear Fuels plc: issues faced when a research project formed the basis of litigation.J R Statistical Soc [Am] 1996;159:41-7.

30 Wakeford R. Epidemiology and litigation-the Sellafield childhood leukaemia cases.J R Statistical Soc [Am] 1998;161:313-25.

31 StataCorp. Stata statistical software; release 5.0. Texas: Stata Corporation, 1996.

32 Office of Population Censuses and Surveys. Cancer statistics registrations. London: HMSO, 1987. (Series MB1 No 20.)

33 Bailar JC, Ederer F. Significance factors for the ratio of a Poisson variable to its expectation. Biometrics 1964;20:639-43.

34 Breslow NE, Day NE. Statistical methods in cancer research. Vol II. The analysis of cohort studies. Lyons: International Agency for Research on Cancer, 1980.

35 Huber PJ. The behaviour of maximum likelihood estimates under non-standard conditions. In: Proceedings of the fifth Berkeley symposium on mathematical statistics and probability. Berkley, CA: University of California Press 1967;1:221-33.

36 Rogers WH. Sg17: Regression standard errors in clustered samples. Stata Technical Bulletin 1993;13:19-23.

37 Skinner CJ. Introduction to part A. In: Skinner CJ, Holt D, Smith TMF, eds. Analysis of complex surveys. New York: John Wiley, 1989.

38 Korn EL, Graubard BI. Simultaneous testing of regression coefficients with complex data: use of Bonferoni t statistics. American Statistician 1990;44:270-6.

39 Beral V, Inskip H, Fraser P, Booth M, Coleman D, Rose G. Mortality of employees of the United Kingdom Atomic Energy Authority, 1946-1979. BMJ 1985;291:440-7.

40 Smith PG, Douglas AJ. Mortality of workers at the Sellafield plant of British Nuclear Fuels. BMJ 1986;293:845-54.

41 Beral V, Fraser P, Carpenter L, Booth M, Brown A, Rose G. Mortality of employees of the Atomic Weapons Establishment 1951-1982. BMJ 1988;297:757-70.

42 Kendall G, Muirhead C, MacGibbon B, O'Hagan J, Conquest J, Goodill A, et al. First analysis of the national registry for radiation workers: occupational exposure to iomising radiation and mortality. Chilton: National Radiological Protection Board, 1992. (NRPB-R251.)

43 Douglas AJ, Omar RZ, Smith PG. Cancer mortality and morbidity among workers of the Sellafield plant of British Nuclear Fuels. Br J Cancer 1994;70:1232-43.

44 Carpenter L, Higgins C, Douglas A, Fraser P, Beral V, Smith P. Combined analysis of mortality in three United Kingdom nuclear industry workforces, 1946-1988. Radiation Res 1994;138:224-38.

45 McLaughlin JR, Anderson TW, Clarke EA, King W. Occupational exposure of fathers to ionizing radiation and the risk of leukaemia in offspring-a case-control study. Ottowa: Atomic Energy Control Board 1992. (AECB project No 7.157.1.)

46 Pobel D, Viel JF. Case-control study of leukaemia among young people near La Hague nuclear reprocessing plant: the environmental hypothesis revisited. BMJ 1997;314:101-6.

(Accepted 21 April 1999)

\section{Endpiece Spitting of blood}

Probably most doctors would agree that haemoptysis is a significant symptom and an indication for full investigation to discover the cause. I was interested, therefore, to read an 18th century list of possible causes in The Family Companion for Health (F Fayram, London, 1929):

"A Straining to vomit, to go to Stool, Labour, Running, Fighting, violent Sneezing, a strong inspiration, Shouting aloud, Fencing too hard and long together, carrying of great Loads, or lifting them up, holding one's Breath too long, too great Straining in Coition, Dancing too much and too long, excessive Laughter; hence Wrestlers, Racers, Hunters, Singers, Trumpeters, Dancers, Porters and such like, are subject to Spittings of Blood.

Amongst all the Passions of the Mind, Anger is the chief Cause of this Distemper."

Perhaps the list of causes really illustrates how common pulmonary tuberculosis was at that time.

Submitted by A P Radford, retired general practitioner, Taunton 